\title{
Errorless learning in newborn chicks
}

\author{
P. W. ROBINSON, D. F. FOSTER, and C. V. BRIDGES \\ Brigham Young University, Provo, Utah 84602
}

\begin{abstract}
Nine newborn chicks were trained on a successive, red-green discrimination task. At the start of discrimination training, the intensity of the green light $(\mathrm{S}-)$ was slowly faded in for six chicks and was presented at full intensity for the remaining three. While meeting the response criterion for errorless learning, the chicks conditioned with the fading procedure made five times fewer errors than the full-intensity group. It was concluded that preexperimental error experience is not a necessary condition for the development of errorless learning.
\end{abstract}

Traditionally, discrimination learning has been considered as a means by which the environment comes to control an organism's behavior through reinforcing that behavior in the presence of one stimulus $(\mathrm{S}+)$ while withholding the reinforcement in the presence of another stimulus $(\mathrm{S}-)$. Terrace (1963) demonstrated, however, that the occurrence of errors, responses to $\mathrm{S}-$, in the training situation is not necessary for discrimination learning to occur. He trained pigeons to discriminate between a red and a green stimulus-response key without any response being made to the green key ( $\mathrm{S}-$ ). Having trained the birds to peck a red key $(\mathrm{S}+)$, he slowly faded in the intensity and duration of $S$ - from a dark key presented for $5 \mathrm{sec}$ to a fully illuminated green key presented for $3 \mathrm{~min}$ at a time. As yet, the reason why a fading procedure can be effective in developing an errorless discrimination is unclear. One explanation as to why fading works is that organisms have had an extensive history of go/no-go discrimination training in their natural or laboratory environments. As a result they have been conditioned not to respond when the positive stimulus is abruptly removed, as it is at the beginning of the fading procedure. This explanation is in accordance with Lashley and Wade's (1946) contention that once an organism has been reinforced for emitting a particular response he will not selectively refrain from responding to stimuli other than $\mathrm{S}+$ until he has experienced differential reinforcement from responding to $S+$ and its alternatives.

While a number of studies have both supported and opposed the idea that a history of differential reinforcement is a necessary condition for the acquisition of stimulus control, no previous investigation has addressed the specific issue concerning the effects of preexperimental history on errorless learning. The present investigation addressed this issue by attempting to condition an errorless discrimination in newborn chicks. Several aspects of previous investigations suggest the possibility that errorless learning cannot occur unless an organism has a rather extensive preexperimental history. First, all previous publications on errorless learning have involved either adult nonhumans (e.g., Marsh \& Johnson, 1968; Schusterman, Kellogg, \& Rice, 1965; Terrace $1963,1966,1969$ ) or human subjects at least 4 years of age (e.g., Sidman \& Stoddard, 1967; Storm \& Robinson, 1973; Terrace, 1974). Second, Warren, Brookshire, Ball and Reynolds (1960) conditioned a position and brightness discrimination in chicks ranging from 3 to 63 days old. They found a progressive decrease with age in the number of trials needed to master the discrimination. It has also been noted that older chicks make lower time scores in learning mazes and a problem box than younger birds (Cruze, 1938).

It was felt that the results of the present experiment could provide answers to several questions: Is errorless learning possible in chickens? Is a fading procedure effective in developing errorless learning in chickens? Is errorless learning obtained when organisms have a limited history of trial and error learning prior 10 experimental training? Using a modification of Terrace's (1963) fading procedure, newborn chicks were taught a successive color discrimination, with red serving as $\mathrm{S}+$ and green as $\mathrm{S}-$.

\section{METHOD}

\section{Subjects}

Nine newly hatched White Leghorn chicks served as subjects and were maintained on an 11-h food deprivation schedule. The chicks were housed in two $46 \times 56 \times 41 \mathrm{~cm}$ Coleman chests with white interiors, both illuminated and heated by a $40-\mathrm{W}$ frosted bulb. Each chick was worked with every 12 -h, at which tume the experimental sessions consısted of 20 reinforced trials.

\footnotetext{
Apparatus

The discrimination training took place in a specially constructed chamber with $14.6 \times 14.6 \times 20.3 \mathrm{~cm}$ internal dimensions. A Piezoelectric stimulus-response key (Altman \& Hull, 1973), $2.5 \mathrm{~cm}$ in diameter, was located $5 \mathrm{~cm}$ above the floor and $7 \mathrm{~cm}$ from the corner, and could be adjusted to $5 \mathrm{~g}$ pressure to be sensitıve enough to pick up the peckıng of the newborn chicks. An IEE 12 stimulus display cell was mounted behind the key, $w 1$ th a 500 -ohm Mallory $P 1$ variable resistor placed in series with the key light so its intensity could be varied from zero to full intensitv.
} 
Procedure

The chicks did not respond to magazıne training un the first day, so they were left in the experimental chamber for at least 15 min to acclimatize them to the chamber environment. On the second day, magazine training and shaping were begun with one important variation from standard magazine and shaping procedures. After every 5.0 -sec reinforcement period in which the house and key lights were turned off, there was a 5.0 -sec intertrial interval in which the key light remained dark and the houselight was on. After that period, during which no shaping or magazine iraining was attempted, the key was illuminated red and shaping continued. Each response to the red key produced reinforcement (Purina Starter Mash) and was defined as a correct response, while any response to the dark kev, which later became $\mathrm{S}-$, was defined as an error. None of the birds struck the dark key during shaping.

After being shaped to respond to $S+$, the chicks were randomly divided into two groups, with six of the nine chicks being placed in Group I. For Group I, the intensity of the key during the 5-sec period following reinforcement was increased from zero to full intensity green $(\mathrm{S}-)$ by decreasing the amount of resistance in the line by 25 ohms during every fifth reinforcement period. Once 300 ohms were removed, the steps were 10 ohms rather than 25 until full intensity $\mathbf{S}-$ was reached. Group I chicks were terminated once they had completed five consecutive sessions with no responding to $S$ - at full intensity. After shaping, $S-$ was introduced immediately at full intensity during the 5 -sec period following reinforcement for Group II chicks. Group II chicks were run for 13 sessions which was roughly equivalent to Group I's experience with $S$ - at full intensity. Any response to $\mathrm{S}-$ by chicks in either group reset the timer controlling the

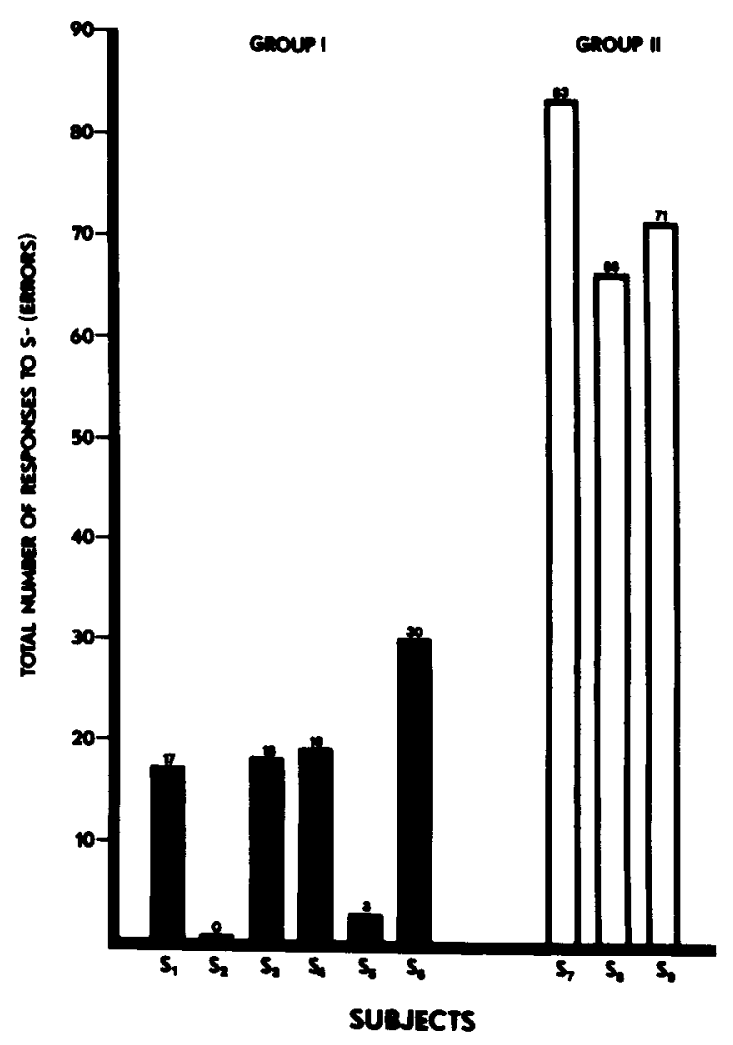

Figure 1. Total number of responses to the green key $(S-)$ emitted by the Group I chicks $\left(S_{1}-S_{6}\right)$ and the Group II chicks $\left(\mathbf{S}_{7}, \mathbf{S}_{8}, \mathbf{S}_{9}\right)$. duration of $S-$, thereby delaying presentation of $S+$ for another $5 \mathrm{sec}$.

\section{RESULTS AND DISCUSSION}

Figure 1 shows the number of errors emitted by all nine chicks during the experiment. All six subjects of Group I learned the discrimination errorlesslydefined as making 40 or less responses to $\mathrm{S}$ - (Karpicke \& Hearst, 1975; Terrace, 1963; Wilkie \& Ramer, 1974) - with all six going five consecutive sessions without pecking $\mathrm{S}-$. The chicks in Group II emitted over five times as many responses to $S-(p<.001)$. Although the number of errors declined substantially over sessions for chicks in Group II, there was no indication that any of them would go five consecutive sessions without making at least one response to $S-$. There is no evidence here to suggest that training an errorless discrimination in newborn chicks is any more difficult than errorless discriminations we have trained in adult pigeons and chickens.

The first result of this investigation is to demonstrate that errorless learning can be obtained in chickens. Currently, errorless learning has been demonstrated in relatively few species [e.g., humans, Terrace (1974); pigeons, Terrace (1963); sea lions, Schusterman et al. (1965)]. Second, although errorless learning is possible in newborn chicks, special conditionifig procedures (e.g., fading in $\mathrm{S}-$ ) are necessary for it to occur. The results from the chicks in Group II are consistent with previou findings involving newborn chicks [e.g., Malott (1968); Warren et al. (1960)], which indicate that they will not refrain from responding to $\mathrm{S}-$ if $\mathrm{S}+$ and $\mathrm{S}-$ are both presented from the outset and the only difference between them when first presented is hue. The need for special conditioning procedures to obtain errorless learning in chicks is also consistent with results obtained in pigeons (e.g., Terrace, 1963) and children (Storm \& Robinson, 1973). Third, a fading procedure can be used to obtain errorless learning with chickens. Several investigators (e.g., Haude, 1973; Karpicke \& Hearst, 1975) have reported difficulties in obtaining errorless learning using a fading procedure. For example, Karpicke and Hearst (1975) reported that only 9 out of 61 of their pigeons on the fading procedure acquired the color discrimination errorlessly. Six out of six of the chicks in the present investigation acquired the discrimination errorlessly with the fading procedure. Fourth, since errorless learning can be shown in newly hatched domestic chicks, an extensive prior history of discrimination learning in either a natural or laboratory environment would not seem necessary for this kind of learning. The results suggest that errorless learning is a primary phenomenon, and not dependent upon errors as a part of prior experience. 


\section{REFERENCES}

Altman, F., \& Hull, L. D. Piezoelectric pecking key. Journal of the Experimental Analysis of Behavior, 1973, 19, 289-291.

Cruze, W. W. Maturity and learning ability. Psychological Monograph, 1938, 50, 49-65.

HAUDE, R. H. Failure to establish errorless discrimination in monkeys. Perceptual and Motor Skills, 1973, 37, 299-304.

KARPICKE, J., \& Hearst, E. Inhibitory control and errorless discrimination learning. Journal of the Experimental Analysis of Behavior, 1975, 23, 159-166.

LASHley, K. S., \& WAdE, M. The Pavlovian theory of generalization. Psychological Review, 1946, 53, 72-87.

Malott, M. K. Stimulus control in stimulus-deprived chickens. Journal of Comparative and Physiological Psychology, 1968, 66. $276-282$.

Marsh, G., \& Johnson, R. Discrimination reversal following learning without errors. Psychonomic Science, 1968, 10, 261-262.

Schusterman, R. J., Kellogg, W. N., \& Rice, C. E. Underwater visual discrimination by the California sea lion. Science, 1965, 147, 1594-1596.

Srdman, M., \& STOdDaRd, L. T. The effectiveness of fading in programming a simultaneous form discrimination for retarded children. Journal of the Experimental Analysis of Behavior, 1\%7, 10, 3-15.

Storm, R., \& Robinson, P. W. Application of a graded-choice procedure to obtain errorless learning in children. Journal of the Experimental Analysis of Behavior, 1973, 20, 405-410.
Terrace, H. S. Discrimination learning with and without "errors." Journal of the Experimental Analysts of Behavior. $1963,6,1-27$.

Terrace, H. S. Behavioral contrast and the peak shift: Effects of extended discrimination training. Journal of the Experimental Analysis of Behavior, 1966, 9, 613-617.

TERRACE, H. S. Extinction of a discriminative operant following discrimination learning with and without errors. Journal of the Experimental Analysis of Behavior, 1969, 12, 571-582.

TERRACE, H. S. On the nature of non-responding in discrimination learning with and without errors. Journal of the Experimental Analysis of Behavior, 1974, 22, 151-159.

Warren, J. M., Hrookshire, N. H., Ball, G. G., \& REYNolds, D. V. Reversal learning by White Leghorn chicks. Journal of Comparative and Physiological Psychology, $1960,53,371-375$.

Wrikie, D., \& RAmer, D. Errotless discrimination established by differential autoshaping. Journal of the Experimental Analysis of Behavior, 1974, 22, 333-340.

(Received for publication August 22, 1975; revision accepted January 15, 1976.) 